\title{
Energy Harvesting Technology for turbocompounding automotive engines with waste-gate valve
}

\author{
Vittorio Usai ${ }^{1}$, Silvia Marelli ${ }^{1}$, Avinash Renuke $^{1}$, and Alberto Traverso ${ }^{1}$ \\ ${ }^{1}$ University of Genoa, Italy
}

\begin{abstract}
The reduction of $\mathrm{CO}_{2}$ and, more generally, GHG (Green House Gases) emissions imposed by the European Commission (EC) and the Environmental Protection Agency (EPA) for passenger cars has driven the automotive industry to develop technological solutions to limit exhaust emissions and fuel consumption, without compromising vehicle performance and drivability. In a mid-term scenario, hybrid powertrain and Internal Combustion Engine (ICE) downsizing represent the present trend in vehicle technology to reduce fuel consumption and $\mathrm{CO}_{2}$ emissions. Concerning downsizing concept, to maintain a reasonable power level in small engines, the application of turbocharging is mandatory for both Spark Ignition (SI) and Diesel engines. Following this aspect, the possibility to recover the residual energy of the exhaust gases is becoming more and more attractive, as demonstrated by several studies around the world. One method to recover exhaust gas energy from ICEs is the adoption of turbocompounding technology to recover sensible energy left in the exhaust gas by-passed through the waste-gate valve. In the paper, an innovative option of advanced boosting system is investigated through a bladeless micro expander, promising attractive cost-competitiveness. The numerical activity was developed on the basis of experimental data measured on a waste-gated turbocharger for downsized SI automotive engines. To this aim, mass flow rate through the by-pass valve and the turbine impeller was measured for different waste-gate settings in steady-state conditions at the turbocharger test bench of the University of Genoa. The paper shows that significant electrical power can be harvested from the waste-gate gases, up to $94 \%$ of compressor power, contributing to fuel consumption reduction.
\end{abstract}

\section{Introduction}

The legislation for internal combustion engines is very restrictive in terms of pollutant emissions and fuel consumption. In order to reduce fuel consumption and exhaust emissions an improvement of the thermal efficiency of the propulsion system is necessary. In modern automotive spark ignition engines $30 \div 40 \%$ of the fuel energy is carried away in exhaust gases: power levels from 4.6 to $120 \mathrm{~kW}$ at temperatures up to $900{ }^{\circ} \mathrm{C}$ are wasted $[1,2]$. For

Contact Information: Silvia Marelli (Associate Professor), DIME, University of Genoa; silvia.marelli@unige.it 
these reasons heat recovery technologies are very attractive to improve modern engine efficiency.

One option is represented by thermoelectric generators based on Peltier-Seeback effects, which provide directly electric energy from thermal energy. The delay in the application of this technology is due to the low efficiency, high cost and the unavailability of a large amount of surface in automotive applications [3, 4].

Another option is represented by Organic Rankine Cycles (ORC), promising significant fuel savings (about 15\% of improvement for brake specific fuel consumption). An ORC includes at least four components: an evaporator, an expander, a condenser and a pump, but more complex structures could be necessary in order to recover other low-grade heat sources on board. Constraints to this technology are given by the high cost, the limited space for ORC integration on vehicles, its weight, and the waste heat release instabilities during part load operations [2, 5-7].

The turbo-compound technology is the latest method investigated to recover energy from exhaust gases. It consists of a power turbine added into the exhaust line. This additional component could be mechanically linked to the engine (mechanical turbo-compoud) or to an electric generator (electric turbo-compound). Mechanical turbo-compound is usually installed on large diesel engines for heavy-duty application and the fixed gear transmission does not allow the optimization of the turbine efficiency in a large operating range.

The most interesting application of electric turbo-compound requires the installation of a motor-generator electrical machine on the turbocharger shaft in order to extract exceeding power from the turbine and assist the compressor during high load requests, improving the dynamic response of the turbocharged engine [8]. Many Authors focused the attention on a low pressure turbine placed downstream the main turbocharger [9-12] in order to achieve the maximum power extraction from the exhaust gases. The problem of this architecture is related to the back pressure to the engine that could cause a rise of fuel consumption due to higher pumping losses, requiring also an additional calibration of the powertrain.

In this preliminary work, the solution proposed by the Internal Combustion Engine Group (ICEG) and the Thermochemical Power Group (TPG) of the University of Genoa, Italy, is to recover energy from the exhaust gases minimizing the impact on the internal combustion engine. A power turbine could be installed in parallel to the main turbine. The waste-gate valve of the main turbocharger is kept closed for standard operation; when the exceeding mass flow rate needs to be discharged through the waste gate, such a quantity expands now through the new innovative power turbine, harvesting net power. A Tesla turbine is proposed by the Authors for this application. The Tesla turbomachinery, invented by Nikola Tesla in $1913[13,14]$ consists of an array of parallel thin disks very close to each other, separated by spacers and assembled on a shaft, forming a rotor. The rotor is fitted in a cylindrical housing with its ends closed by plates properly fitted with bearings to hold the rotor shaft [15]. The fluid enters tangentially into the turbine from the nozzle. The momentum of the moving fluid is transferred to disks because of viscosity and adhesion. The friction force generated by the fluid transfers this momentum to the disks, hence producing power at the shaft. Conventional bladed turbines impose manufacturing limitations and higher cost, which hinder their implementation on a small scale. This research focuses on investigation of feasibility of Tesla type turbines for waste heat recovery application, thanks to their low cost, simple manufacturing, promising efficiency on a small scale.

In the paper the results of an experimental campaign regarding the steady flow characterization of a turbocharger waste-gated turbine for gasoline engine application are presented. The turbine behavior is analyzed in the ICEG test rig operating at the University of Genoa, under different openings of the waste-gate valve. In addition, the swallowing capacity of the sole waste-gate valve is measured, closing the turbine wheel inlet. A preliminary performance map of Tesla turbine for this application is obtained by a three- 
dimensional Computational Fluid Dynamic (CFD) analysis, referring to an actual prototype, currently under tests. The Tesla turbine map is used to estimate the potential power harvestable from the waste-gate gases, under different operating conditions.

\section{Experimental Activity}

The experimental campaign on the main turbocharger was developed on a small unit for downsized spark ignition engine (IHI RHF3). Its single entry nozzleless radial flow turbine is fitted with a waste-gate valve.

The experimental performance maps have been measured at the turbocharger test facility of the University of Genoa (Fig. 1), fully described in a previous paper [16].

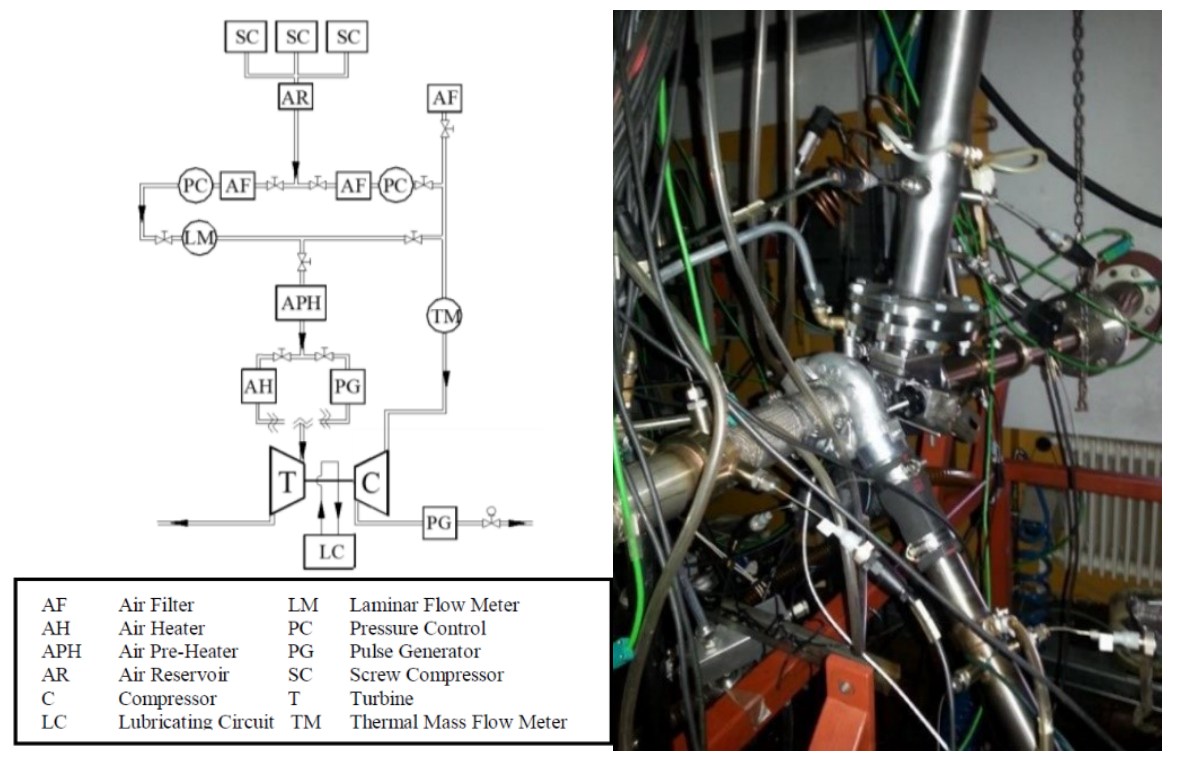

(a)

(b)

Fig. 1. (a) ICEG turbocharger test facility; (b) turbocharger installed at the test bench

The test facility is especially suited to test turbochargers thanks to the availability of two independent feeding line for both turbine and compressor. Three electrical screw compressors provide a maximum of $0.6 \mathrm{~kg} / \mathrm{s}$ of dry air at 8 bar. An electric air heaters station allows to increase turbine inlet temperature up to $750{ }^{\circ} \mathrm{C}$. Pulse generators [17] could be used to replicate the turbocharger behaviour under unsteady flow typically occurring in intake and exhaust engine circuits. Static pressure is measured through strain gauge transducers (with an accuracy of $0.15 \%$ of the full scale) placed upstream and downstream of the compressor and the turbine, a high frequency response piezoresistive pressure transducer is installed downstream of the compressor, to detect surge phenomena $[16,18]$. Total temperatures are measured through platinum resistance thermometers (with an accuracy of $\pm 0.15{ }^{\circ} \mathrm{C} \pm 0.2 \%$ of measured value) and thermocouples. A thermal mass flow meter (with an accuracy of $\pm 0.9 \%$ measured value and $\pm 0.05 \%$ of the full scale) is used to measure compressor mass flow, while a laminar flow meter (with an accuracy of $\pm 2 \%$ of the measured value) is used to measure the mass flow through the turbine. An eddy current probe (with an accuracy of $\pm 0.009 \%$ of the measured value) mounted close to the compressor wheel is adopted to measure turbocharger rotational speed. The waste-gate valve opening is measured by a rotary 
variable resistance sensor with an accuracy of \pm 2 degrees $[17,19]$. All measurements are recorded by an automatic data acquisition system developed in LabVIEW ${ }^{\circledR}$ environment.

Turbine characteristic curves at different waste-gate valve positions and different rotational speed factors have been measured. Result reported in Fig. 2 are performed in "cold conditions", corresponding to a turbine inlet temperature equal to $80^{\circ} \mathrm{C}$. The measured values are scaled on the conventional non-dimensional parameter to take into account the density variation of the inlet flow, as following reported:

- Turbine rotational speed factor $(\mathrm{rpm} / \sqrt{\mathrm{K}})$

$$
n_{t}=n / \sqrt{T_{T 3}}
$$

- $\quad$ Expansion ratio (total-to-static) (-)

$$
\varepsilon_{t}=p_{T 3} / p_{S 4}
$$

- $\quad$ Mass flow rate factor $(\mathrm{kg} \sqrt{\mathrm{K}} /$ ( $\mathrm{s}$ bar $))$

$$
\Phi_{t}=\left(M_{t} * \sqrt{ } T_{T 3}\right) / p_{T 3}
$$

where:

$\mathrm{n}$ is the turbocharger rotational speed;

$\mathrm{T}_{\mathrm{T} 3}$ is the turbine inlet total temperature;

$\mathrm{p}_{\mathrm{T} 3}$ is the turbine inlet total pressure;

$\mathrm{p}_{\mathrm{S} 4}$ is the turbine outlet static pressure;

$\mathrm{M}_{\mathrm{t}}$ is the turbine mass flow rate.

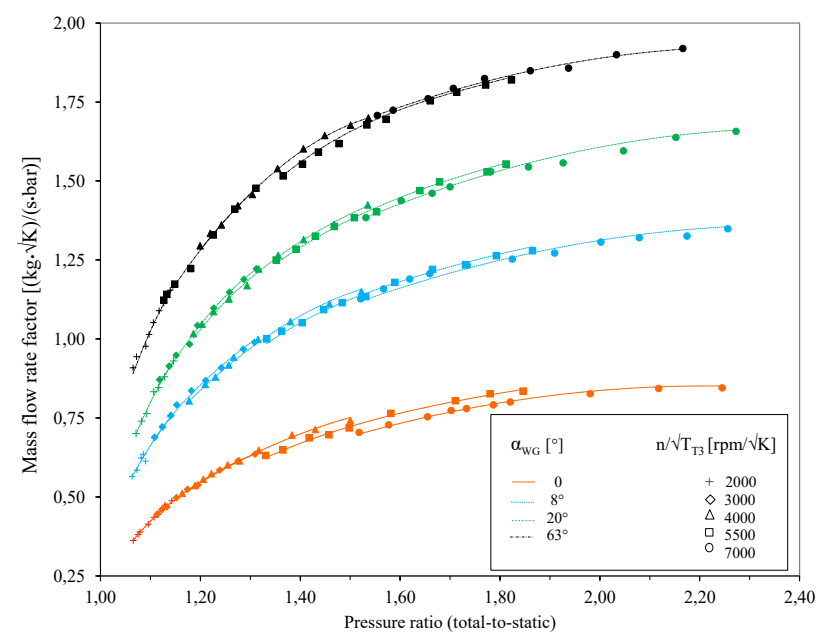

Fig. 2. Steady state turbocharger turbine swallowing capacity.

In order to extend the definition of turbine performance map, the compressor is used as a dynamometer varying the power absorption of the compressor. In Fig. 2 steady state mass flow characteristics are reported referring to different levels of turbine rotational speed factor ranging from 2000 to $7000 \mathrm{rpm} / \sqrt{\mathrm{K}}$ and waste-gate valve openings (fully closed, partially open $\left(8^{\circ}\right.$ and $\left.20^{\circ}\right)$, and totally open $60^{\circ}$ ). Turbine curves were defined in a wider operating 
range than that considered in the turbocharger manufacturer maps, being the latter referred only to closed waste-gate valve condition.

A substantial increase of the mass flow rate factor is observed in the open waste-gate region, confirming that there is a substantial by-pass flow contribution, often greater than the mass flowing through the turbine rotor. In the same conditions, the turbine overall efficiency decreased significantly, since this quantity is referred to the isentropic work of the whole mass flowing through the system (turbine rotor and by-pass port) [17].

In order to provide the experimental data necessary to the turbine CFD model, the swallowing capacity of the waste-gate valve has been calculated starting from the measured characteristic curves of the turbine, when the by-pass is open (Fig.2), by subtracting the mass flow rate factor through the impeller when the waste-gate valve is kept closed. This approach does not take into account the interaction between the rotor and the waste gate valve. Interactions between the two flow components can take place within the turbine volute casing and lead to some modifications in mass flow rate and efficiency, as previously observed by the Authors [17,19]. However, for this preliminary analysis, this assumption has been adopted. Actually, if calculated data are compared with those previously measured through an anemometric system located in the pipe downstream the by-pass port [17, 19] (see black dots in fig. 3), a good agreement can be observed, confirming the acceptable accuracy of the approach here followed, as a first approximation. During the typical operation of the engine, the mass flow rate through the waste-gate valve reaches often values higher than the mass flow through the impeller. For this reason, the proposed solution of a turbine instead of the waste-gate valve could be a good option to recover significant amount of energy, improving the global efficiency of the propulsion system, without imposing any additional backpressure to the engine and without requiring any additional calibration.

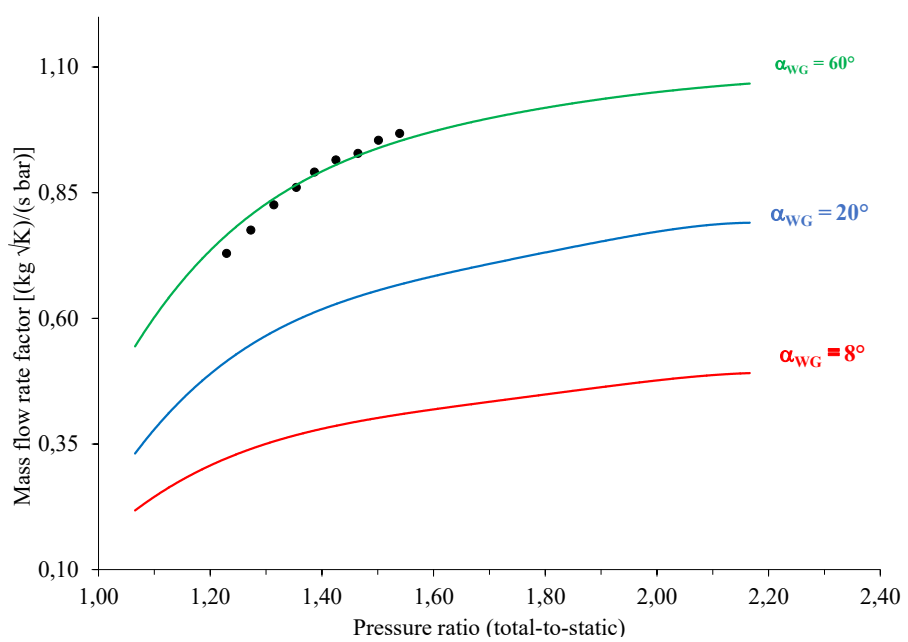

Fig. 3. Waste-gate valve swallowing capacity at different openings.

\section{Power Turbine Performance}

A Tesla turbine of approximately $3 \mathrm{~kW}$ design power is considered for this application. It is a slightly modified version of an existing Tesla air prototype of $3 \mathrm{~kW}$. This design for wastegate replacement consists of 160 disks of $120 \mathrm{~mm}$ outer diameter and $60 \mathrm{~mm}$ inner diameter (discharge hole periphery). Disks are $0.1 \mathrm{~mm}$ thick with $0.1 \mathrm{~mm}$ gap between them. There 
are eight convergent nozzles placed around periphery at equal distance. There is provision to control nozzles individually depending upon the required opening of the waste-gate valve. A high-speed permanent magnet generator is coupled to the shaft to draw the power generated by the turbine. The generator is incorporated into the body of the turbine to make the machine more compact as shown in Fig 4(a).

A 3D computational fluid dynamic (CFD) is performed to calculate the performance of the turbine for waste heat recovery application. A 3D model domain consists of half disk and half gap to save computational efforts and time. A grid independence test is performed to get the most accurate results in less fine mesh to save computational time. A structured mesh is created using ICEM Ansys 19.2 to get faster convergence. CFD simulations are performed for steady, turbulent and compressible supersonic flow. For this purpose, 3D, double precision, density-based solver in Fluent 19.2 is used with energy equation model and transition SST (shear stress transport) to accurately resolve flow at the wall. Convergence for residual is tracked till 10-6 along with convergence following parameters: outlet tangential velocity, outlet total temperature, torque on disks and mass flux.

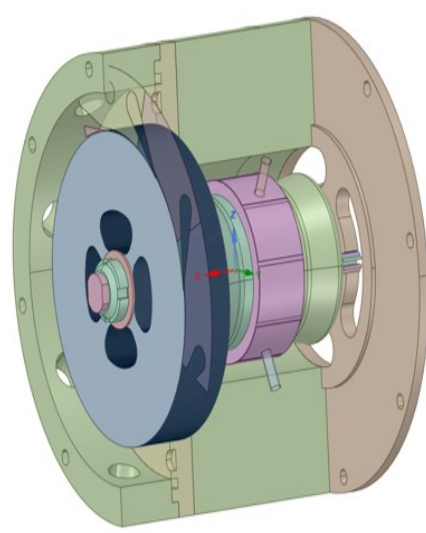

(a)

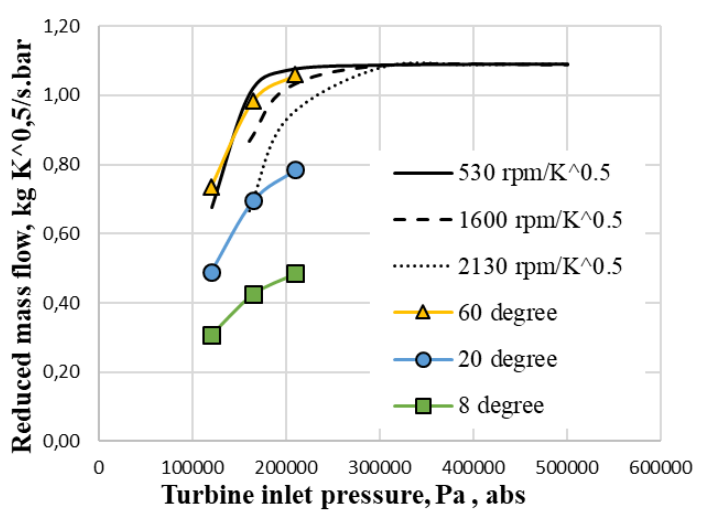

(b)

Fig. 4. (a) Turbine assembly cross section showing nozzles, rotor and generator in single housing; (b) Turbine characteristic curves and waste-gate valve swallowing capacity for different openings

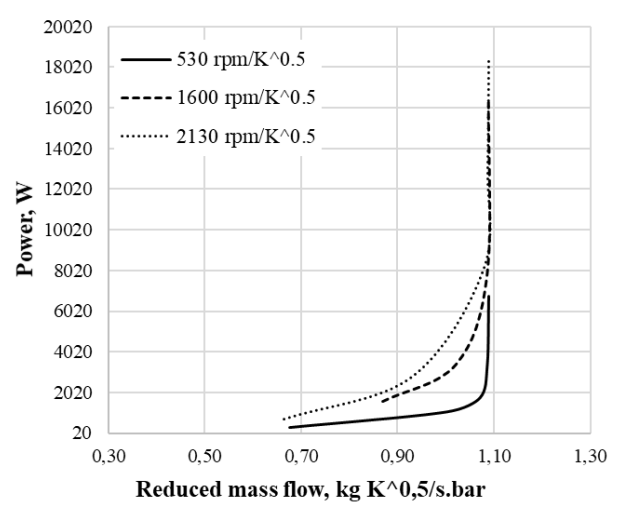

(a)

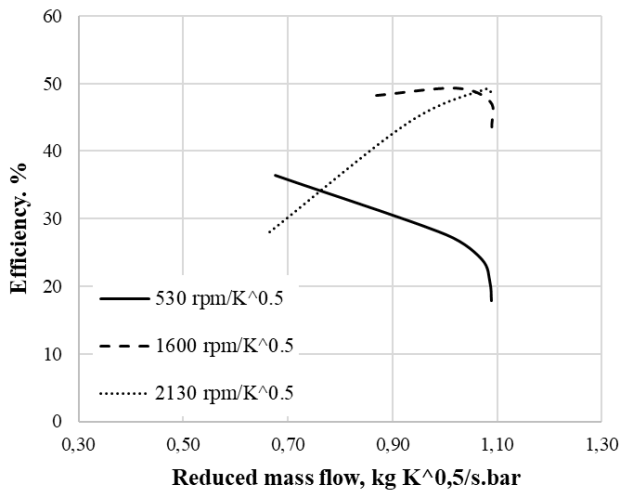

(b)

Fig. 5. (a) Turbine power versus mass flow rate factor for different rotational speed factors; (b) Turbine total to static efficiency versus mass flow rate factor at different rotational speed factors 
Turbine characteristics curves are shown in Fig. 4(b) together with waste gate valve capacity for different openings. It could be observed that the waste gate valve capacity flow curves for 60 degree opening correspond to the turbine curve for a speed factor of 2130 $\mathrm{rpm} / \mathrm{K}^{0.5}$, being operated with all the 8 nozzles open. From Figure 5 (a) and (b) turbine efficiency of $57 \%$ and power of more than $3 \mathrm{~kW}$ could be evaluated. Table 1 shows the comparison of predicted turbine power with measured compressor power. The maximum harvested turbine power could reach $94 \%$ of the power used by the compressor for the maximum waste gate opening degree and for higher pressure ratio.

Table 1. Comparison of predicted turbine power vs. compressor power

\begin{tabular}{|cccccc|}
\hline $\begin{array}{c}\text { WG } \\
\text { valve } \\
\text { opening }\end{array}$ & $\begin{array}{c}\text { Turbine } \\
\text { inlet } \\
\text { pressure, } \\
\text { bar }\end{array}$ & $\begin{array}{c}\text { Predicted } \\
\text { Turbine } \\
\text { power, } \\
\text { W }\end{array}$ & $\begin{array}{c}\text { Rotational } \\
\text { speed of } \\
\text { turbine, } \\
\text { rpm }\end{array}$ & $\begin{array}{c}\text { Measured } \\
\text { compressor } \\
\text { Power, W }\end{array}$ & $\begin{array}{c}\text { \% of Turbine } \\
\text { power over } \\
\text { compressor } \\
\text { power }\end{array}$ \\
\hline \multirow{2}{*}{60} & 1,20 & 327 & 10000 & 370 & 88 \\
& 1,65 & 1088 & 10000 & 1780 & 61 \\
\hline \multirow{2}{*}{20} & 2,10 & 3774 & 30000 & 4020 & 94 \\
\hline & 1,20 & NA & NA & 370 & NA \\
& 1,65 & 892 & 40000 & 1780 & 50 \\
\hline
\end{tabular}

\section{Conclusion}

In this paper, the possibility to replace a waste-gate valve in an actual turbocharger with a Tesla turbine energy harvester has been investigated as turbo-compounding option. The experimental data from an actual turbocharger has been used to derive the waste-gate shallowing capacity. A specifically designed Tesla turbine has been considered, assuming to be able to regulate the inlet flow, ensuring the same swallowing capacity of the waste-gate: in such a way, the waste-gate could be potentially replaced without any need of recalibration of the engine. The electrical power which can be harvested from the waste-gate gases, is up to $94 \%$ of the compressor power, thus demonstrating that a significant saving in fuel consumption could be achieved by adopting this technology.

\section{References}

1. R. El Chammas, and D. Clodic, "Combined Cycle for Hybrid Vehicles," SAE Technical Paper 2005-01-1171; (2005). doi:10.4271/2005-01-1171.

2. F. Zhou, E. Dede, and S. Joshi, "Application of Rankine Cycle to Passenger Vehicle Waste Heat Recovery - A Review," SAE Int. J. Mater. Manf. 9(2); (2016). doi:10.4271/2016-01-0178.

3. S. S. Rathore, A. Singh, P. Kumar, N. Alam, et al., "Review of Exhaust Gas Heat Recovery Mechanism for Internal Combustion Engine Using Thermoelectric Principle," SAE Technical Paper 2018-01-1363; (2018). doi:10.4271/2018-01-1363.

4. J. Fairbanks "Thermoelectric applications in vehicles" status 2008. In: $6^{\text {th }}$ European conference of thermoelectrics, Paris, France; (2008). 
5. T. Wang, Y. Zhang, Z. Peng, G. Shu. "A review of researches on thermal exhaust heat recovery with Rankine cycle.” Renew Sustain Energy Rev 15: 2862-71; (2011).

6. C. Sprouse, c. Depcik "Review of organic Rankine cycles for internal combustion engine exhaust waste heat recovery." Appl Therm Eng 51:711-22; (2013).

7. M. Tahani, M. Javan, M. Biglari “A comprehensive study on waste heat recovery from internal combustion engines using organic Rankine cycle.” Therm Sci 17(2):611-24; (2013).

8. Cooper, A., Bassett, M., Hall, J., Harrington, A. et al., "HyPACE - Hybrid Petrol Advance Combustion Engine - Advanced Boosting System for Extended Stoichiometric Operation and Improved Dynamic Response," SAE Technical Paper 2019-01-0325; (2019). doi:10.4271/2019-01-0325

9. A. Bin Mamat, R. Martinez-Botas, S. Rajoo, A. Romagnoli, "Waste heat recovery using a novel high performance low pressure turbine for electric turbocompounding in downsized gasoline engines: experimental and computational analysis", Energy 90218 234; (2015).

10. G. Pasini, G. Lutzemberger, S. Frigo, S. Marelli, M. Ceraolo, R. Gentili, M. Capobianco, "Evaluation of an electric turbo compound system for SI engines: A numerical approach.” Applied Energy 162 527-540; (2016).

11. A. Bin Mamat, A. Romagnoli, R. Martinez-Botas, "Characterisation of a low pressure turbine for turbocompounding applications in a heavily downsized mild-hybrid gasoline engine", Energy 64 3-16; (2014).

12. G. Pasini, S. Frigo, S. Marelli, "Numerical comparison of an electric turbo compound applied to a SI and a CI engine", in: ASME 2015 Internal Combustion Engine Division Fall Technical Conference, November 8-11, Texas, USA; (2015).

13. Tesla, N., 1913, "Turbine", US Patent 1061206.

14. Tesla, N.,1913, "Fluid propulsion", US Patent 1061142.

15. Renuke, A., Vannoni, A., Traverso, A., and Pascenti, M., 2019, "Experimental Investigation of Tesla Micro Expanders", Proceedings: ASME TurboExpo'19, Phoenix, USA

16. S. Marelli, G. Marmorato, M. Capobianco, "Evaluation of heat transfer effects in small turbochargers by theoretical model and its experimental validation", in: Energy, Elsevier, Volume 112, Pages 264-272, doi:10.1016/j.energy.2016.06.067; (2016).

17. M. Capobianco, S. Marelli "Experimental investigation into the pulsating flow performance of a turbocharger turbine in the closed and open waste-gate region." In: Proceedings of 9th international conference on turbochargers and turbocharging; p. 37386; (2010).

18. S. Marelli, A. Misley, A. Taylor, P. Silvestri, M. Capobianco, M. Canova, "Experimental Investigation on Surge Phenomena in an Automotive Turbocharger Compressor", SAE Technical Paper 2018-01-0976; (2018). doi: 10.4271/2018-01-0976

19. V. De Bellis, S. Marelli, F. Bozza, M. Capobianco, "Advanced Numerical/Experimental Methods for the Analysis of a Waste-Gated Turbocharger Turbine," SAE Int. J. Engines 7(1); (2014). doi:10.4271/2014-01-1079. 